\title{
Optimal maintenance system for offshore wind turbines
}

\author{
Pérez M. ${ }^{1}$, García E. ${ }^{1}$, Morant F. ${ }^{1}$, Correcher A. ${ }^{1}$ and Quiles E. ${ }^{1}$ \\ ${ }^{1}$ Department of Fault Diagnosis, Industrial Automation Institute (AI2) \\ E.T.S.I.I., Valencia University \\ 46022 Valencia (Spain)
}

Phone: (+34) 963877000 ext 88448, e-mail: mjopecol@upv.es, egarciam@isa.upv.es, fmorant@isa.upv.es, ancorsal@upvnet.upv.es, equiles@ isa.upv.es

\begin{abstract}
In the last years, the industry of wind power generators has developed in many aspects. The offshore plants have some benefits over the onshore ones but their implementation is really expensive.

Based in that cost, this paper describes the importance of applying an optimal maintenance based in priorities and cost. It also studies the maintenance types and proposes a scheme of maintenance for offshore plants.
\end{abstract}

\section{Key words}

Wind power turbine, offshore, optimal maintenance, cost, priority, petri net

\section{Introduction}

Wind power is one of the renewable energies most used all over the world, but if the industry wants to expand it has to improve the system and the generation versus cost relationship. This sector has lately trend to invest in offshore conditions, due to the high power generation, strong winds, etc. Nevertheless, this type of wind turbines has some problems that should be solved as soon as possible. One of these problems is that the turbines are far away of the coast, and some aspects like maintenance have a high cost.

\section{Maintenance}

The maintenance of an offshore power turbine includes so many factors to consider that make this task really complicated (spare, ships, costs, etc).

By investing in operation and maintenance we could improve efficiency and effectiveness, reduce downtime losses and increase the availability of wind farms [5].

This paper describes a method to optimize the maintenance system for a wind power turbine offshore plant, considering priorities and using Petri Nets and Fuzzy control systems.

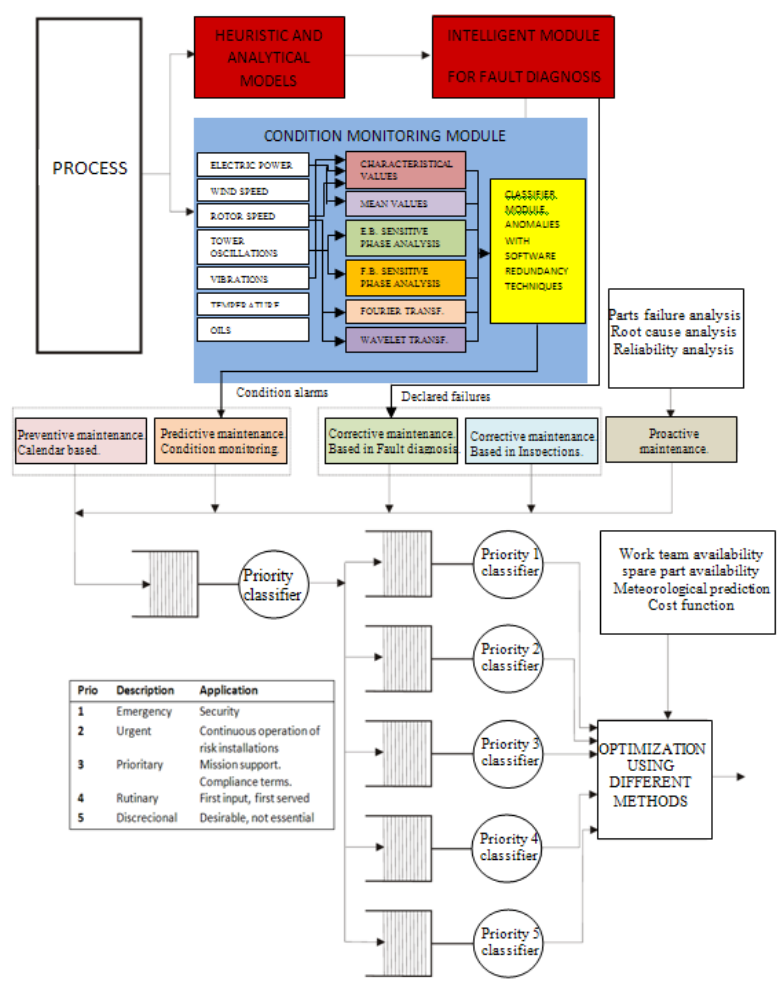

Fig. 1: Maintenance scheme

In figure 1 we propose a scheme for the maintenance [6]. As we can see, the fault diagnosis module and the condition monitoring modules are the inputs for the predictive and corrective maintenance type. The other inputs are based on calendar, inspections or investigation.

\section{A. Maintenance types}

There are some different types of maintenance that could be applied to offshore farms (Table I). If we want to design an optimal maintenance system, it should include all these aspects, perfectly coordinated and working together to assure that the failure is solved by the appropriate method depends on the cause and the situation. 
Table I: Maintenance Types

\begin{tabular}{|l|l|}
\hline \multicolumn{1}{|c|}{ TYPE } & \multicolumn{1}{c|}{ DESCRIPTION } \\
\hline Preventive & Repairs based on calendar \\
\hline Predictive & $\begin{array}{l}\text { Using condition monitoring to determine } \\
\text { the machine health }\end{array}$ \\
\hline $\begin{array}{l}\text { Corrective (fault } \\
\text { diagnosis) }\end{array}$ & Based on declared failures. \\
\hline $\begin{array}{l}\text { Corrective } \\
\text { (inspections) }\end{array}$ & $\begin{array}{l}\text { Based on failures detected in periodic } \\
\text { revisions. }\end{array}$ \\
\hline Proactive & Analysis of parts, reliability, etc. \\
\hline
\end{tabular}

\section{B. Considerations}

There are some aspects to consider if we want to design an optimal maintenance system. The first thing we consider is the priority of the task. This parameter is set based on the consequences of the failure, the frequency, the time the machine is in downtime, the time we have to repair the failure, etc.

With this factor, we propose a system that puts in order the maintenance tasks in different priority classification modules. These modules are dynamic, and they use the priority and the available time to reorganize inside them.

The next task of the system is to analyze the rest of the considered factors (Table II) in order to group the maintenance tasks that can be performed and optimize the ship travel and reduce costs. This analysis is made using Petri Nets, considering every possibility that could take place (unavailability of materials, unsuitable weather conditions, etc) and acting differently in each situation (Fig. 2).

Table II: Aspects to consider

\begin{tabular}{|l|l|}
\hline \multicolumn{1}{|c|}{ CONSIDERATIONS } & \multicolumn{1}{c|}{ DESCRIPTION } \\
\hline Work team availability & $\begin{array}{l}\text { Check if the personal team needed } \\
\text { to solve the problem is available }\end{array}$ \\
\hline Material availability & Spare parts, components, pieces... \\
\hline Weather conditions & $\begin{array}{l}\text { Every repair requires different } \\
\text { conditions (wind, swell, etc.) }\end{array}$ \\
\hline Cost function & $\begin{array}{l}\text { Analyzes the economic aspects to } \\
\text { determine the better moment to } \\
\text { execute the task. }\end{array}$ \\
\hline Tasks in execution wait & $\begin{array}{l}\text { Associate to the waiting tasks that } \\
\text { can be carry out. }\end{array}$ \\
\hline
\end{tabular}

When a maintenance task can't be execute, it stays in a state of execution wait until the considerations are fulfilled, updating the available time to take care of the task in order to request the material or the work team if the priority is high. To create a maintenance order, the system checks these waiting tasks ready to be executed, the available time and the priorities, allowing the maintenance system to decide the better moment to create the order and execute the maintenance.

\section{Petri Net}

The system uses a petri net to evaluate the conditions of the different tasks. The various maintenance types (Table
I) feed the system, including the relevant information in each case. This system is divided in subsystems:

- Material and Work Team Subsystem.

- Optimization and Revision Subsystem.

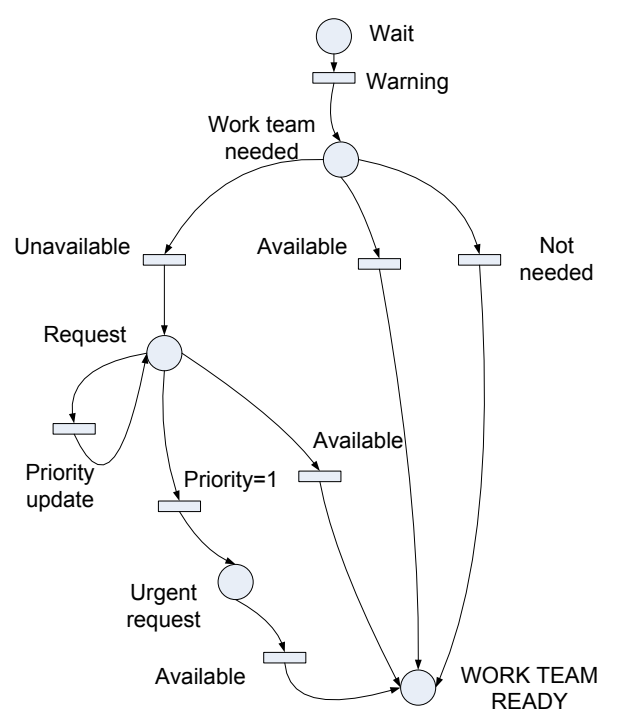

Fig. 2: Petri Net for the Work Team

The first subsystem (Figures 2 and 3) analyzes the requirements of every maintenance order and prepares the order to be executed. The work team and the material are consulted simultaneously in two different petri nets. As we can see in the figures, the first step is to analyze if the maintenance order requires material or personal, and request if necessary. When the requests are fulfilled, the order stays in the Ready State.

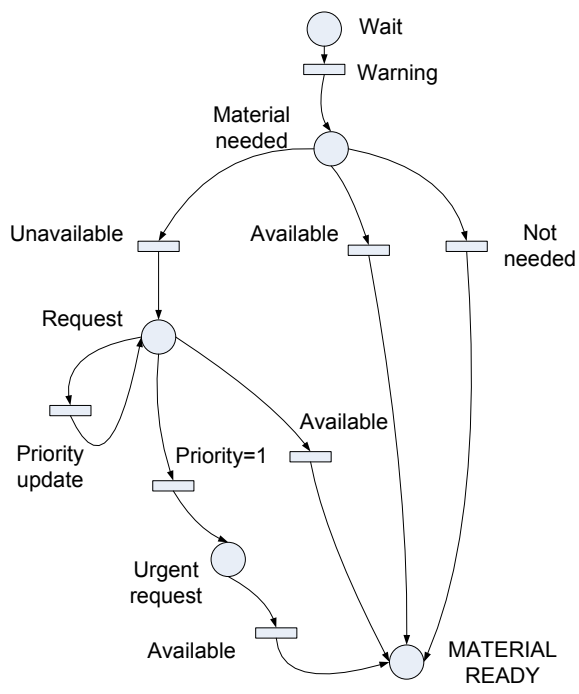

Fig. 3: Petri Net for the Material

The second subsystem (Figure 4) studies the possibilities and calculates the optimal solution, and it also revises that the requirements are fulfilled. 


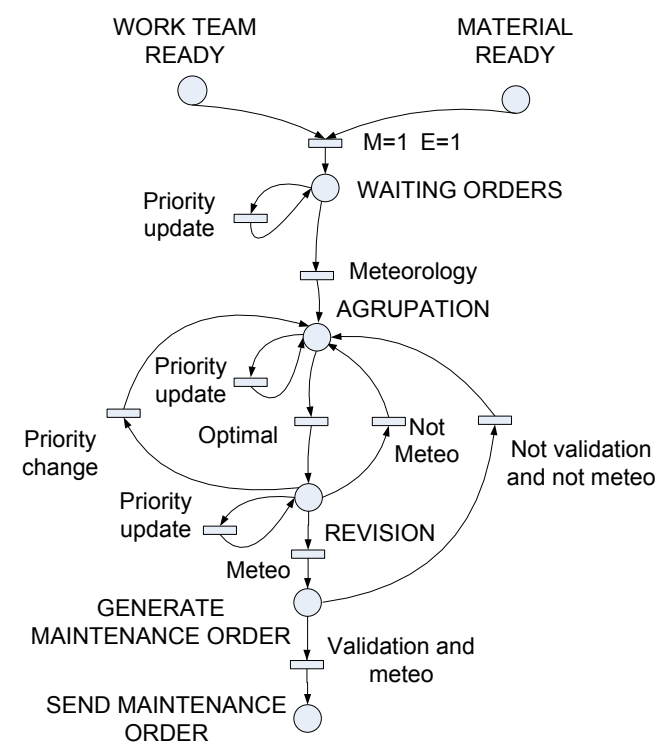

Fig. 4: Petri Net for the Optimization and Revision Subsystem

The subsystem starts working if the material and the work team are available for the maintenance order. The order stays in a waiting state, updating the priority, until the meteorology conditions are acceptable.

In the grouping state the system considers the diverse possibilities of transport as ships of different capacity or helicopter, very used in the last year to take care of orders that don't involve spare parts or materials. It also considers the orders that can be executed and the cost. With these parameters, the system calculates the options that could be realized. This program is greatly developed in section 4.

For the optimization program we propose three different methods to calculate the optimal solution. The number of methods is justified because each one has different parameters and the solutions could differ. Depending on the most important parameters or the characteristics of the system, the experts should analyze and use the best method for the application, or use all of them and compare the results to make a decision.

The methods we propose are:

- Based in constraints

- Based in preferences interface

- Using Fuzzy Logic

Once the system has an optimal solution calculated, the orders to be executed stay in a revision state. In this state the priorities must be updated to ensure the system that there are no changes on the available time. If there are changes, the orders must return to the grouping state and recalculate the optimal solution.

If the meteorological conditions are fulfilled, the orders continue to the next state, to generate a global maintenance order including the orders to resolve previously grouped, and waiting for a validation.

\section{Grouping system}

The parameters that should be considered in the grouping system are:

- Cost Function

- Availability in the ship

- Waiting orders

- Resolved orders

With these parameters, as we could see in Figure 5, the system groups the orders that can be resolved in different options. These options depend of the available ships or helicopter, the cost of the global option and the orders that every option can resolve. It is also important to consider the priority of the tasks that stay waiting due to the ship capacity, because if they are high priority tasks must be resolved.
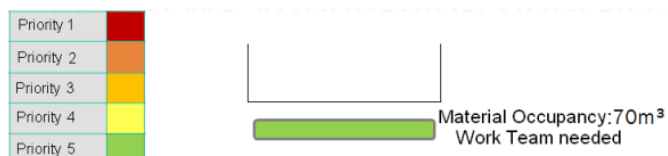

Ship 1: $203 \mathrm{~m}^{3}$

Ship 2: $487 \mathrm{~m}^{3} \quad$ Ship $3: 950 \mathrm{~m}^{3} \quad$ Helicopter
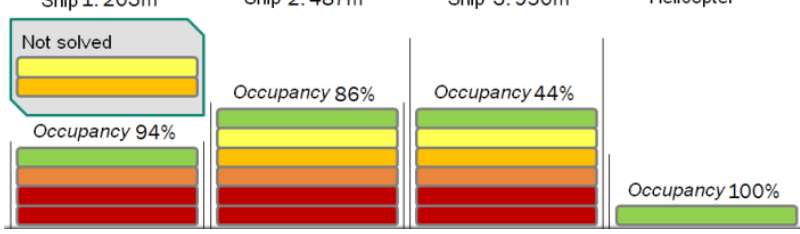

Fig. 5: Grouping example

The orders must be grouped in order. That means that the priority 1 tasks should be the firsts to group. After that, the priority 2 orders and so on. Between orders of the same priority, the available time decides the first's tasks to group.

\section{Optimization}

The maintenance orders wait in the groping state for the optimal moment to create a maintenance order. For this search, based in the options calculated in the grouping state, we propose a system that gives a value to every parameter considered.

Whit these values, and using the Optimization formula, we are able to choose the optimal solution by using three different methods.

\section{a) Constraints}

In the developed example, we have four parameters to consider: Cost of the ship, Priority 1 tasks that are solved, priority of the rest of tasks to develop, and occupation of the ship.

By the constraints method, we select the most important parameter to optimize, in this case the cost. For the rest of the parameters, we assign a restriction like this:

- Ship occupancy $>50$

- Priority 1 tasks attended $>80 \%$ 
- Priority rest of tasks: Not tasks unattended or priority $>3$

In this case, the optimization function should minimize the cost, satisfying the restrictions.

\section{b) Preference interface}

The preference interface methodology is based in defining ranges for the parameters and assigns to them a label: High desirable, desirable, tolerable, not desirable or unacceptable. For every option calculated in the grouping system, it assigns the corresponding label, as we can see in Figure 6. The labels and values are just an example, they are not meaningful.

\begin{tabular}{|c|c|c|c|c|c|c|}
\hline Function & $\begin{array}{c}\text { High } \\
\text { desirable }\end{array}$ & Desirable & Tolerable & \multicolumn{2}{|c|}{$\begin{array}{c}\text { Not } \\
\text { desirable }\end{array}$} & $\begin{array}{c}\text { Not } \\
\text { Acceptable }\end{array}$ \\
\hline Tasks P1 & $x=90$ & $80-90$ & $70 \sim 80$ & \multicolumn{2}{|c|}{$50 \sim 70$} & $<50$ \\
\hline Occupancy & $80 \sim 100$ & $60 \sim 80$ & $50 \sim 60$ & \multicolumn{2}{|c|}{$20-50$} & $<20$ \\
\hline Cost & $>100000$ & $\begin{array}{l}70000 \sim \\
100000\end{array}$ & $\frac{30000 \sim}{70000}$ & \multicolumn{2}{|c|}{$\begin{array}{l}10000 \\
30000\end{array}$} & $<10000$ \\
\hline \multirow{5}{*}{$\begin{array}{l}\text { Rest of } \\
\text { tasks }\end{array}$} & 0 or 5 & 4 & 3 & 2 & & 1 \\
\hline & Function & Tasks P1 & \multicolumn{2}{|c|}{ Occupancy } & Cost & $\begin{array}{l}\text { Rest of } \\
\text { tasks }\end{array}$ \\
\hline & Option 1 & $H D$ & \multicolumn{2}{|l|}{ D } & $H D$ & $U$ \\
\hline & Option 2 & $D$ & \multicolumn{2}{|l|}{$T$} & D & $D$ \\
\hline & Option 3 & HD & \multicolumn{2}{|l|}{ HD } & U & ND \\
\hline
\end{tabular}

Fig. 6: Preference interface example

The system analyzes the labels and calculates the optimal option. For this decision, it is better an option with desirable label than with unacceptable, although the rest of the label were higher. In the example in figure 5, the order would be Option 2, Option 1, and Option 3. Between options 2 and 3 they both have an unacceptable label, so the decision is with the next worst label: not desirable.

\section{c) Fuzzy Logic}

The third option we propose is an optimization based in Fuzzy logic. In this method we define a function to optimize and assign adjustable weights to every parameter.

The function should be similar to:

$$
\begin{aligned}
& \text { Optimal Solution }=0 \text { '5xCost }+ \text { 0’3xTasksP1+ } \\
& \text { 0’1xPendingTasks }+ \text { 0'1xShipOccupancy }
\end{aligned}
$$

The weights associated to every parameter are totally adjustable in function of the application or the requirements.

Table II: Ranges definition for the fuzzy system

\begin{tabular}{|l|l|l|}
\hline PARAMETER & RANGE & VALUE \\
\hline Cost & $0-10000 €$ & $0-100$ \\
\hline Tasks p1 & $0-100 \%$ & $0-100$ \\
\hline Occupancy & $0-100 \%$ & $0-100$ \\
\hline
\end{tabular}

The next step is to assign a value for every parameter. The values are assigned to the parameters using fuzzy logic. For this labour we define the range of inputs (parameters) and outputs (values) as we can see in Table II. After that, create the fuzzy system by adjusting the internal rules.
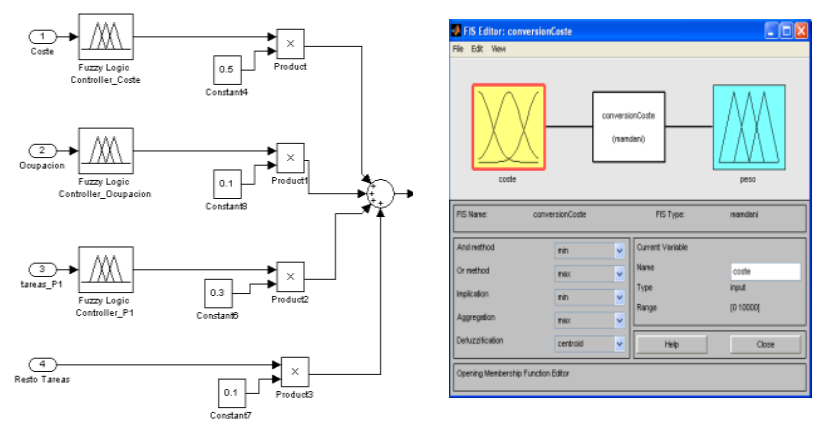

Fig. 7: Optimal solution using Fuzzy Logic

To define the values for the rests of tasks pending to attend, it's better to ascribe that value in function of the priorities of the tasks rather than of the number of tasks waiting. For this, it could be appropriate an assignment as can be seen in Table III.

Table III: Value assignment for pending tasks

\begin{tabular}{|c|c|}
\hline REST OF TASKS & VALUE \\
\hline None & 10 \\
\hline P4,P5 & 8 \\
\hline P3,P4,P5 & 6 \\
\hline P2,P3,P4,P5 & 3 \\
\hline P1,P2,P3,P4,P5 & 1 \\
\hline
\end{tabular}

Finally, the system is implemented in Matlab, and calculates the Optimal Solution function (1) for every possible solution previously worked out in the grouping system. By comparing the results, the solution with a higher value would be the optimal of the options.

\section{Conclusions}

An appropriate maintenance system assures the machine and the plant working for a long time by reducing failures and costs.

In the offshore context the maintenance costs are highly increased by ship costs. The grouping system studies the possibilities in order to create different options based in the available ships or helicopter, calculating the tasks to attend according to the priorities and also considers the occupancy and the cost for every option.

These options are transferred to the optimization system. It uses different methods to parameterize the options and calculate the optimal solution.

The whole system is managed by the petri net designed, as could be seen in figures 2,3 and 4 . 
The general scheme includes all this modules and subsystems and it is really useful to let us make an approximation of the global maintenance system.

If this system is correctly applied, the maintenance costs could be greatly reduced and help the wind energy to become profitable and increase its presence in the renewable energies framework.

\section{References}

[1] M. García, M.A. Sanz and J. Del Pico, "Aplicación de técnicas de inteligencia artificial en el mantenimiento predictivo de aerogeneradores", in IV Jornada de Fiabilidad: Confiabilidad, Las Palmas de G.C., September 2002.

[2] G.J.W. van Bussel "Reliability, availability and maintenance aspects of large-scale offshore wind farms, a concepts study", Delft University of Technology, The Netherlands, MAREC 2001 Conference Proceedings, pages $119-126$.

[3] G.J.W. Bussel van and A.R. Henderson, "State of the art and technology trends for offshore wind energy: operation and maintenance issues", Proceedings of offshore wind energy special topic conference 10-12 December, Brussels, Belgium, EWEA (2001), pp. 1-4.

[4] L.W.M.M. Rademakers, H. Braam, T.S. Obdam, P. Frohböse, N. Kruse, "Assessment and optimization of operation and maintenance of offshore wind turbines", Proceedings of the European wind energy conference, 16-19 June, Madrid, Spain, EWEA (2003) 6 pp.

[5] H.-J. Krokoszinski, "Efficiency and effectiveness of wind farms-keys to cost optimized operation and maintenance", Renewable Energy 28 (14)(2003), pp. 21652178.

[6] García, E., Morant, F., Correcher, A., Quiles E. "Seguimiento de Estado, Diagnóstico de Fallos y Mantenimiento Industrial: una visión integrada." Proceedings of the Novena Semana Tecnológica. 19-23 October 2009. La Habana.Cuba. 